\title{
CLICKS, STOP BURSTS, VOCOIDS AND THE TIMING OF ARTICULATORY GESTURES IN KINYARWANDA
}

\author{
Didier Demolin
}

Laboratoire de phonétique et phonologie, Université Sorbonne Nouvelle, Paris 3

\begin{abstract}
This paper shows that differences in timing and coordination of articulatory gestures in Kinyarwanda's complex consonants trigger the emergence of epiphenomenal clicks. Acoustic and aerodynamic data show that click bursts of weak intensity appear in sequences of front (bilabial or alveolar) and velar nasals. The possible consequences of this phenomenon for sound change are briefly discussed. The emergence of short vocoids due a different timing of articulatory gestures allows discussing the status of syllabic constituents in complex nasal consonants.
\end{abstract}

Keyword: Kinyarwanda, clicks, phonetics, vocoids, articulatory gestures

\section{Introduction}

This paper provides evidence for the existence of epiphenomenal (i.e., non-phonemic) clicks in Kinyarwanda. This phenomenon was noted during a study of the phonetics of Kinyarwanda prenasalized consonants (Demolin \& Delvaux 2001, Demolin, 2007) but was not analyzed at the time. Even if epiphenomenal clicks are not phonemic in the language (occurring randomly as free variants), their presence is an important phenomenon to consider for a number of reasons. The first is because bursts that appear between front and back nasal consonants are clicks of weak intensity. Traill (1995) suggested that from an acoustic perceptual point of view, clicks (at least the [+ abrupt] component) are bursts of stronger intensity when compared to the noise produced at the release of stops. Therefore, he suggested an acoustic similarity between the burst of clicks and the burst produced by stop consonants. This leads to a second (more speculative) point that the bursts might be a possible source for explaining sound changes in some Bantu languages. Indeed, if Traill's hypothesis is confirmed, one possible explanation for the spread of clicks in Southern Bantu languages might be that their emergence has been triggered by the amplification of bursts produced within consonant clusters (i.e., ones already present in the acoustic signal). This hypothesis has never been proven or tested, but data from this paper, which are also relevant to Bantu languages such as Shona (Doke (1931), allow proposing such a hypothesis. This suggests that sound change may have played a role in the spread of clicks in Southern Bantu languages, a possibility discussed in the last section of the paper.

Kinyarwanda and many other Bantu languages, e.g., Ikalanga (Mathangwane 1999) and Shona (Doke 1931), have complex sets of prenasalized consonants in their phonological inventories. According to Jouannet (1983), Kinyarwanda has three sets of complex nasals ${ }^{1}$ : (i) a set of voiced

1 The list of consonants comes from Jouannet (1983). Consonants such as [mh, nh] are not strictly prenasalized because normally prenasalized means that the nasal is at the same place of articulation as the 
and voiceless prenasalized consonants [mh, mb, mf, mv, nh, nd, ns, nz, nf, nz, nc, yh, gg]; (ii) a set of voiced and voiceless labiovelarized prenasalized consonants [mhw, mbg, mvg, nohp̧w, ndgw, nskw, nzgw, nfkw,nzgw, phhw; (iii) a set of voiced and voiceless prenasalized palatalized consonants [mpfy, mbf, ndf, nsc, nhy, nJ]. The labiovelarized consonants show a number of realizations requiring an accurate phonetic description and a solid theoretical account. Variations in the temporal realization of gestures required to produce these complex nasal consonants show that their outcome can have important consequences. A good illustration is seen in the word /ímbgá/ 'dog', realized phonetically as: [ím@gá $]^{2} \sim$ [ímgá] [ímbgá], as shown below. Data in this paper come from data recorded for other purposes and are limited in number. However, the occurrence of click bursts and vocoids for every subject who participated in the study makes the description important for future investigations. Therefore, this paper must be considered as a descriptive contribution to a phenomenon that should receive more detailed attention.

\section{Material and method}

\subsection{Participants and data}

Seven Rwandan speakers from the same region (six women and one man from the north of the country) were recorded reading a word list targeting prenasalized sequences. They were asked to read the words within a small frame sentence vùgá_itfúmì, 'say _ ten times'. Table 1 shows the data analyzed in this paper (see Demolin \& Delvaux 2001 for the complete set of recorded data).

Table 1. Words analyzed in the text. Words in the first column come from Jouannet (1983). The second column contains words from Coupez et al.'s (2005) dictionary. Words are given in their root form, numbers represent class membership, and low tones are not transcribed. The phonetic realizations and variants are discussed in the text.

\begin{tabular}{|l|l|l|}
\hline Jouannet (1983) & Coupez et al. (2005) & Gloss \\
\hline ìmhnèmhnjè & -hweempwe cl.10 & chest hair \\
\hline ímbgá & -bwá cl.9,10 & dog \\
\hline ínhywârò & -twáaro cl.9,10 & weapons \\
\hline índgwârà & -rwáara / -dwáara cl.9,10 & illness \\
\hline ínhwânò & -kwáano cl.9,10 & dowry \\
\hline ìngwè & -gwe cl.9,10 & leopard \\
\hline ùmùnywà & -nwa cl.3,4 & mouth \\
\hline ínhá & -ká cl.9,10 & cow \\
\hline
\end{tabular}

following oral closure. In this case $[\mathrm{mh}, \mathrm{nh}]$ rather represent an aspirated nasal. It should be noted that while Jouannet's aspirated nasals are voiceless, data from this paper show that all seven speakers produced them as voiced in the vast majority of cases. Also, very few occurrences of voiceless nasals were observed in the recorded data. This likely represents dialectal differences rather than errors in transcription.

2 Two symbols will be used in this text to transcribe bursts produced by mechanisms similar to the production of clicks: $[\odot]$ for a click burst following a bilabial nasal [m] preceding a velar nasal [ $\mathrm{n}]$, and [!] for a click burst following an alveolar nasal [n] preceding a velar nasal [n]. 
Table 1 shows substantial differences between Coupez et al. (2005) and Jouannet (1983). Some differences are due simply to the fact that the first author transcribes velarized consonants with a consonant followed by [w], e.g. - bwá 'dog' which corresponds to -bgá for the second. Other differences are likely due to dialectal differences. Data for this paper were recorded from the set of data given in Jouannet. The phonetic realizations are presented in the results section. Differences between the two sets are discussed in section 4 .

\subsection{Material}

Aerodynamic recordings were made using the Physiologia workstation (Teston and Galindo 1990) linked to a data collection system equipped with different transducers. Intraoral pressure (Po), oral and nasal airflows (Afo \& Afn) were recorded simultaneously and synchronized with the acoustic signal recording. Oral airflow measurements were taken with a small flexible silicon mask placed over the mouth. Pharyngeal pressure was recorded with a small flexible plastic tube (ID $2 \mathrm{~mm}$ ) inserted through the nasal cavity into the oro-pharynx region. The setting and transducers used in the experiments are shown in Figure 1. Aerodynamic measurements included Po values in nasal clusters; maximum oral airflow for vocoids and maximum nasal airflow in nasal clusters. In order to obtain a smooth line, aerodynamic plots were low pass filtered at $70 \mathrm{~Hz}$.

Acoustic recordings were made with a High Fidelity microphone set on the hardware piece of equipment connecting the transducers to the computer. The acoustic signal was sampled at 16000 $\mathrm{kHz}$. Spectrograms and audio waveforms were processed with the signal explorer software. ${ }^{3}$ Acoustic measures included duration of nasal clusters without click bursts, with click bursts and with the presence of a vocoid separating the nasal consonants within clusters. Vocoids were also measured for their duration. All spectrograms presented in Figures 2 to 9 are wideband spectrograms, a $5 \mathrm{~ms}$ Hamming window.

Data were collected at the Phonology Laboratory of the Université Libre de Bruxelles. They were made according to the rules of the ethical committee of the Hospital Erasme concerning the participation of human subjects.

3 This software designed by Alain Soquet allows the superimposition of aerodynamic plots (Po, Afo, Afn) on the synchronized acoustic data. 
Figure 1. Setting and transducers used to measure acoustic and parameters. Po, Afo and Afn show the device and places of measurements for: Intraoral pressure, oral airflow and nasal airflow.

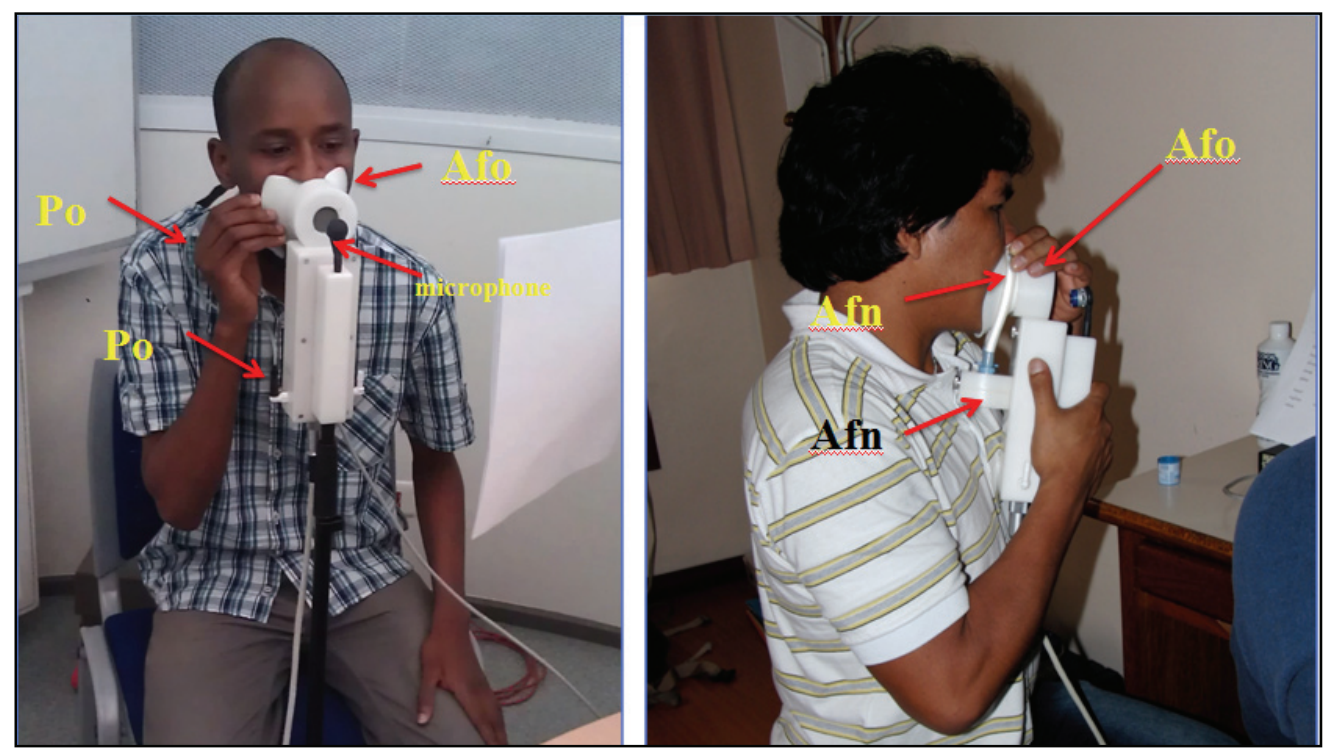

\section{Results}

Data were first examined on spectrograms and waveforms to identify words showing bursts in the middle of nasal clusters involving a sequence of labial [m] or alveolar [n] nasals followed by a

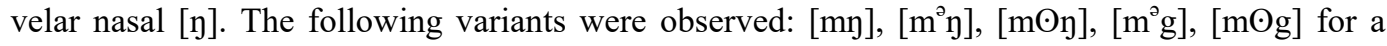
sequence starting with a labial; and $\left[n^{\curvearrowright} \mathrm{\eta}\right],[\mathrm{n} ! \mathrm{n}]$ for a sequence starting with an initial alveolar. Examples illustrating the main variants can be seen in Figures 2 to 9 below. Data from subject 4 were not used because the tube measuring Po was obstructed at times. A total of 37 words was analyzed, including 43 relevant syllables (one word has 2 relevant syllables). The analyzed data shows 18 realizations with a burst and 22 with a small vocoid. Six bursts were realized as [๑] in

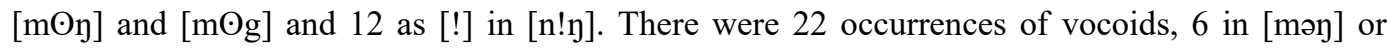
[məg] and 16 in [nəy]. Table 2 summarizes these findings. The average duration of all nasal sequences is $160.9 \mathrm{~ms}$, (SD 27.4), 165.1 (SD 30) for a sequence beginning with a labial and 158.4 (SD 25.3) for a sequence starting with an alveolar consonant. The average duration of the vocoids is $33.9 \mathrm{~ms}$ ( $\mathrm{SD} 8.5$ ). 
Table 2. Occurrences of epiphenomenal clicks and vocoids in nasal clusters involving a sequence of $[+$ front $]-[+$ back] nasals. Numbers give the realizations of variants for each subject (S1 to S7) in the first seven words of table 1. Empty slots indicate that there were no realizations of this sequence for a subject.

\begin{tabular}{|l|l|l|l|l|l|l|l|}
\hline & $[\mathrm{m}]]$ & {$\left[\mathrm{m}^{\curvearrowright} \mathrm{y}\right]$} & {$[\mathrm{m} \odot \mathrm{y}]$} & {$\left[\mathrm{m}^{\curvearrowright} \mathrm{g}\right]$} & {$[\mathrm{m} \odot \mathrm{g}]$} & {$[\mathrm{n} ! \mathrm{n}]$} & {$\left[\mathrm{n}^{\curvearrowright} \mathrm{y}\right]$} \\
\hline S1 & & 1 & 1 & 1 & & & 2 \\
\hline S2 & 2 & & 2 & & 1 & 4 & 1 \\
\hline S3 & 1 & & 1 & & 1 & 2 & 2 \\
\hline S5 & & & & & & 3 & 2 \\
\hline S6 & & 2 & & 1 & & 2 & 3 \\
\hline S7 & 2 & & & 1 & & 1 & 2 \\
\hline
\end{tabular}

\subsection{Variations on the sequence [my]}

3.1.1. Acoustics. Figures 2 and 3 show realizations of the word /ìmhygèmhygè/ 'chest hair'

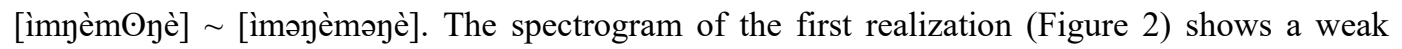
burst between the labial and velar parts of the nasal cluster in the second realization of the nasal sequence. The burst is present at frequencies below $2000 \mathrm{~Hz}$. The double arrow in Figure 2 indicates this. The second realization (Figure 3) shows the presence of a small vocoid between the two nasal consonants. This is shown by a formant around $600 \mathrm{~Hz}$. 
Figure 2. Spectrogram, audio waveform, intraoral pressure (Po), oral airflow (Afo) and nasal airflow (Afn) of the word [ìmnèm@nè].

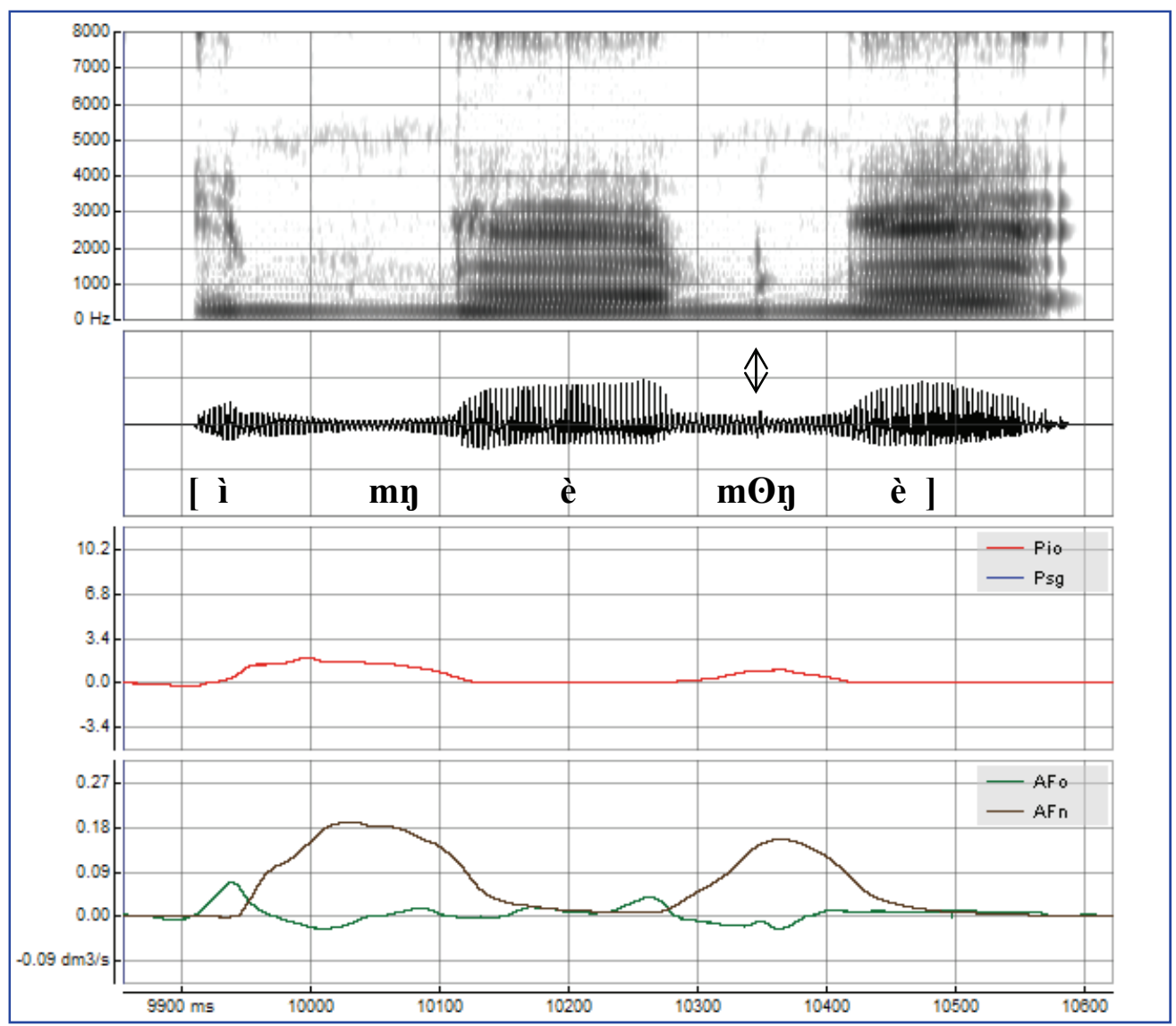

To hear audio click here 
Figure 3. Spectrogram, audio waveform, intraoral pressure (Po), oral airflow (Afo) and nasal airflow (Afn) of the word [ìmª̀̀̀m ${ }^{2}$ yè $]$ (in bold).

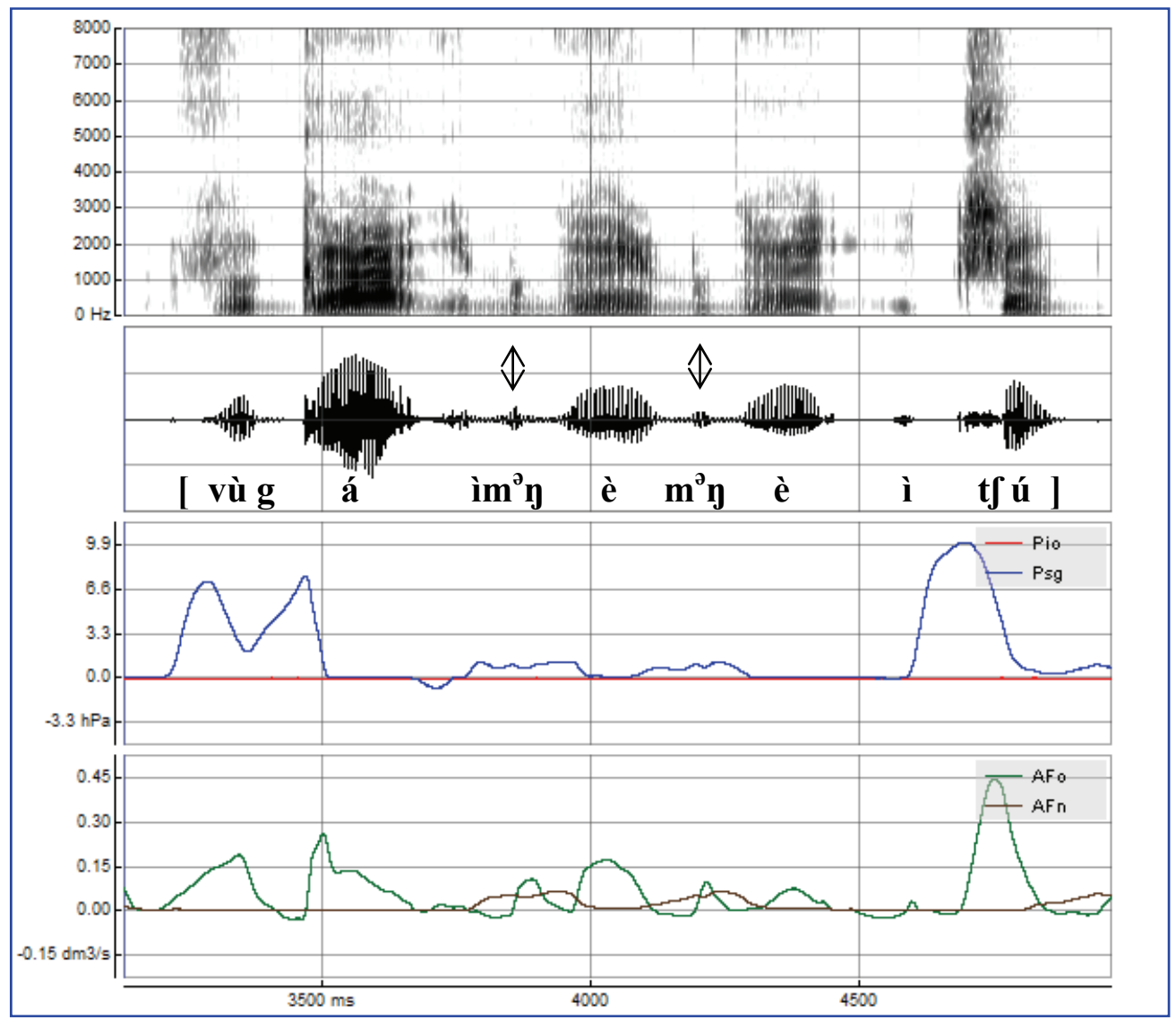

To hear audio click here

3.1.2. Aerodynamics. Po is negligible as expected since there are two nasal consonants. There is a substantial amount of nasal airflow during the nasal cluster with a peak at $0.19 \mathrm{dcm} 3 / \mathrm{s}$ in the first sequence and at $0.16 \mathrm{dm} 3 / \mathrm{s}$ in the second. There is no oral airflow because of closures at the lips and in the velar region to produce the sequence of nasals. The slightly negative Afo observed during the sequences [my, m๑n] accounts for the backward movement of the tongue dorsum to increase the size of the cavity sealed between the lips and the velic closure. In [my] Afo turns to zero at the boundary between [m] and [y]. Afo is still negative when the labial closure is released in the sequence. Differences between both sequences are tiny. They are sufficient to make the weak intensity burst of the click appear in the sequence [m®n]. It is important to note that in both cases there is no increase of Afo at the release of the labial closure. This shows that the velar closure is maintained at this point. The weak intensity burst appearing between the labial and the velar nasals is the result of a slight ingressive influx following the labial release. 
The amount of nasal airflow is weaker in the second realization when compared to the first. The two small vocoids and the vowels show the presence of a weak oral airflow.

\subsection{Variations on the sequence [ñ]}

3.2.1 Acoustics. Figures $4 \mathrm{a}, 4 \mathrm{~b}$ and 5 present three occurrences of the word /ínhygwârò/ 'weapons' [ín!̣̆fwârò] [ín!yhwârò] [ínəywârò]. The spectrograms of the realizations presented in Figure $4 \mathrm{a}$ and $4 \mathrm{~b}$ show that there is a clear burst between the alveolar nasal [n] and the velar nasal [y]. This burst is present at frequencies below $3000 \mathrm{~Hz}$, arrows on the spectrograms and on the waveform indicate this. In Figure $4 \mathrm{a}$, the voiceless nasal velar consonant is followed by a short and weak aspiration before the labial velar glide [w]. Figure $4 \mathrm{~b}$ shows that the velar nasal following the click is voiced. The double burst is likely due to the fact that the release of the alveolar tongue contact is made in two phases.

The last realization (Figure 5) shows the presence of a small vocoid between the two nasal consonants.

Figure 4a. Spectrogram, audio waveform, intraoral pressure (Po), oral airflow (Afo) and nasal airflow (Afn) of the word [ín!ṇwârò] (in bold).

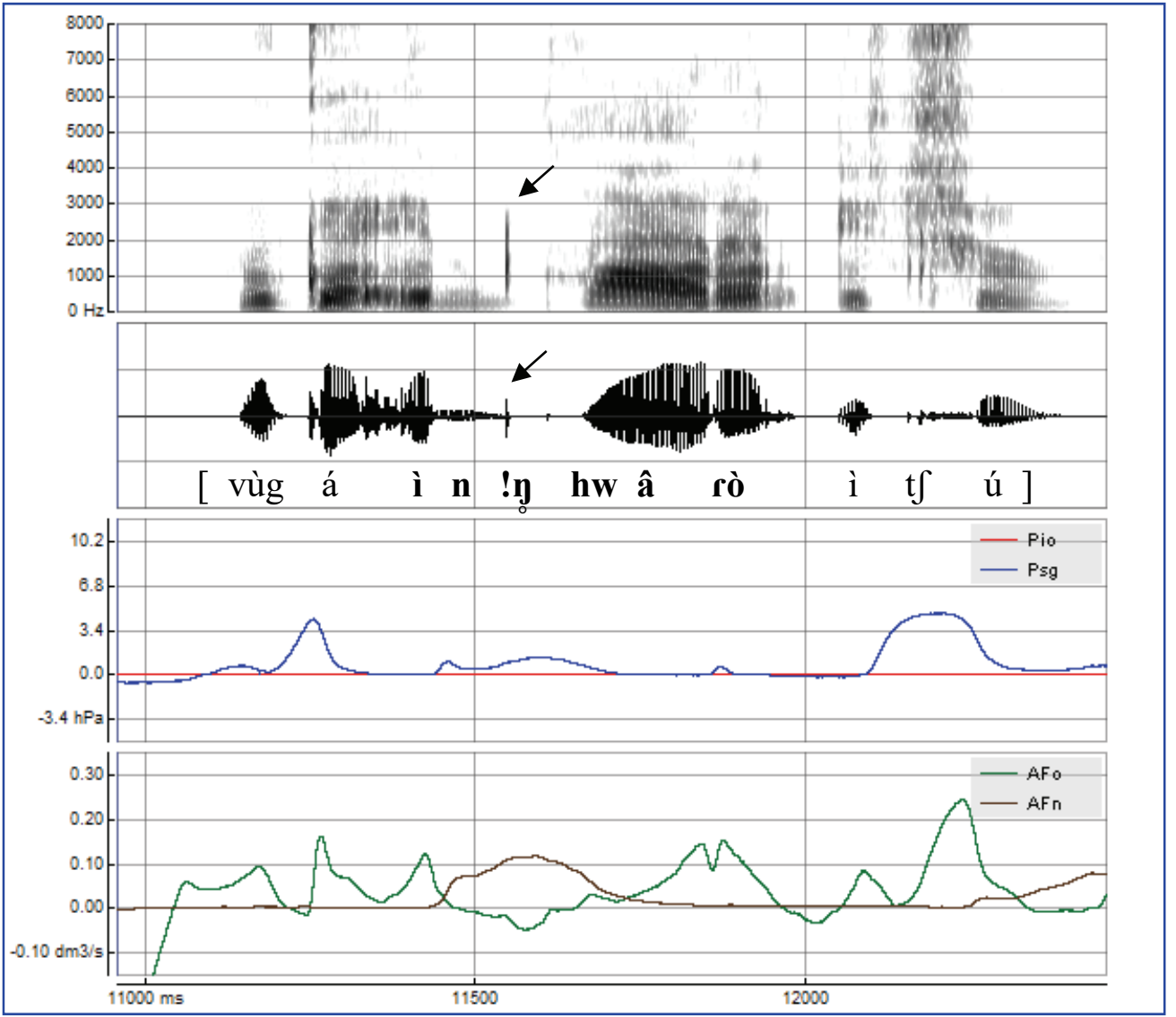

To hear audio click here 
Figure 4b. Spectrogram, audio waveform, intraoral pressure (Po), oral airflow (Afo) and nasal airflow (Afn) of the word [ín! ̣̦wârò] (in bold).

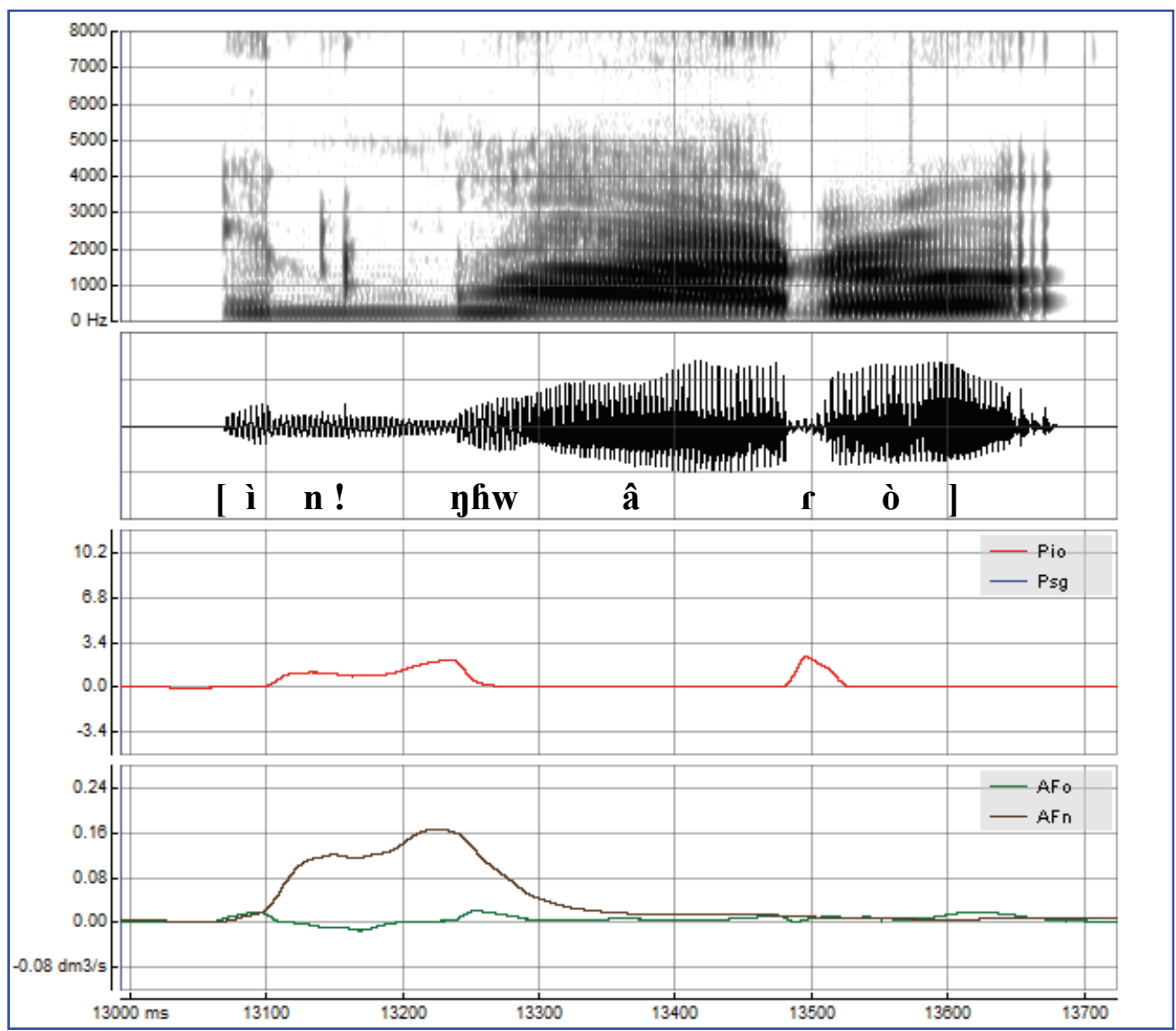

To hear audio click here 
Figure 5. Spectrogram, audio waveform, intraoral pressure (Po), oral airflow (Afo) and nasal airflow (Afn) of the word [ín! ņ:

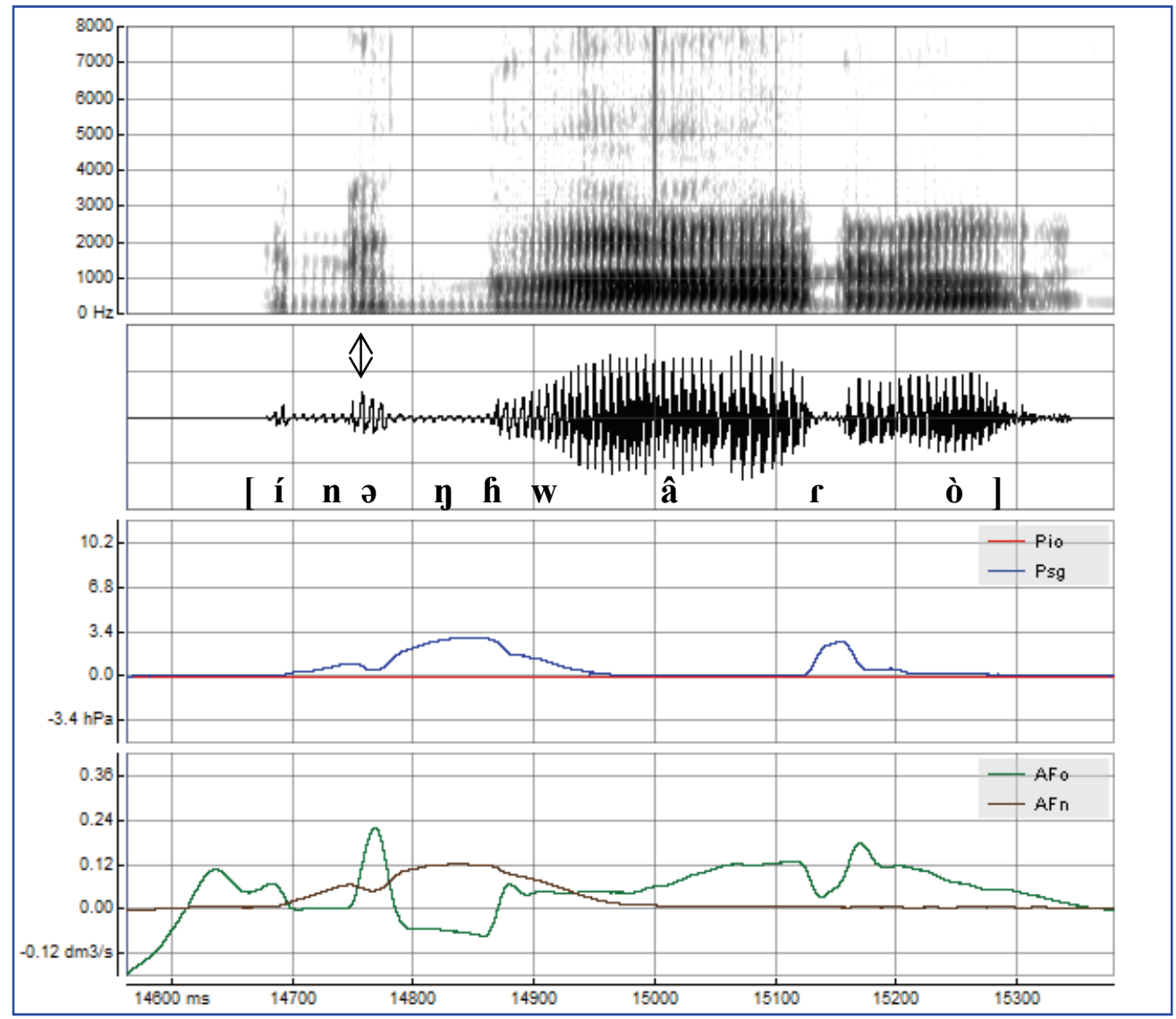

To hear audio click here

3.2.2. Aerodynamics. There is a substantial amount of nasal airflow culminating at $0.12 \mathrm{dcm} 3 / \mathrm{s}$ in the nasal sequence as Figure 4a shows. A small decrease of oral airflow is noticeable between the nasal consonants, at the moment corresponding to the burst. An arrow on Figure 4 indicates this. There is also a small decrease of Po before the moment of the burst's realization. Figure $4 \mathrm{~b}$ shows a small decrease of Afo accompanied by a high Afn before the click. Afn and Po increase during the nasal velar which is quite unusual. This is likely due the fact that the tongue dorsum that is in contact with the velum, makes a backward movement. This presses the velum and reduces the size of the velopharyngeal port. A consequence is that the volume of the pharyngeal cavity diminishes and Po increases. The passage for the nasal airflow is reduced, which reduction accelerates the rate of Afn.

There is a sharp increase of oral airflow when the small vocoid is realized after the alveolar nasal in Figure 5. This is followed by a gradual decrease towards the beginning of the labialvelar glide. 


\subsection{Variations on the sequence $[\mathrm{mbg}]$}

3.3.1. Acoustics. Figures 6 and 7 show two realizations of the word /ímbgá/ 'dog' $\sim$ [ím@gá] [ím gá]. The spectrogram of the first realization (Figure 6) shows a burst at the end of the nasal just before the voiced velar stop [g]. The burst is distinguished at frequencies below $3000 \mathrm{~Hz}$. This is indicated by the arrows and the spectrogram and on the audio waveform.

The second realization (Figure 7) shows the presence of a small vocoid between the bilabial nasal and the voiced velar stop.

Figure 6. Spectrogram, audio waveform, intraoral pressure (Po), oral airflow (Afo) and nasal airflow (Afn) of the word [ím@gá] (in bold).

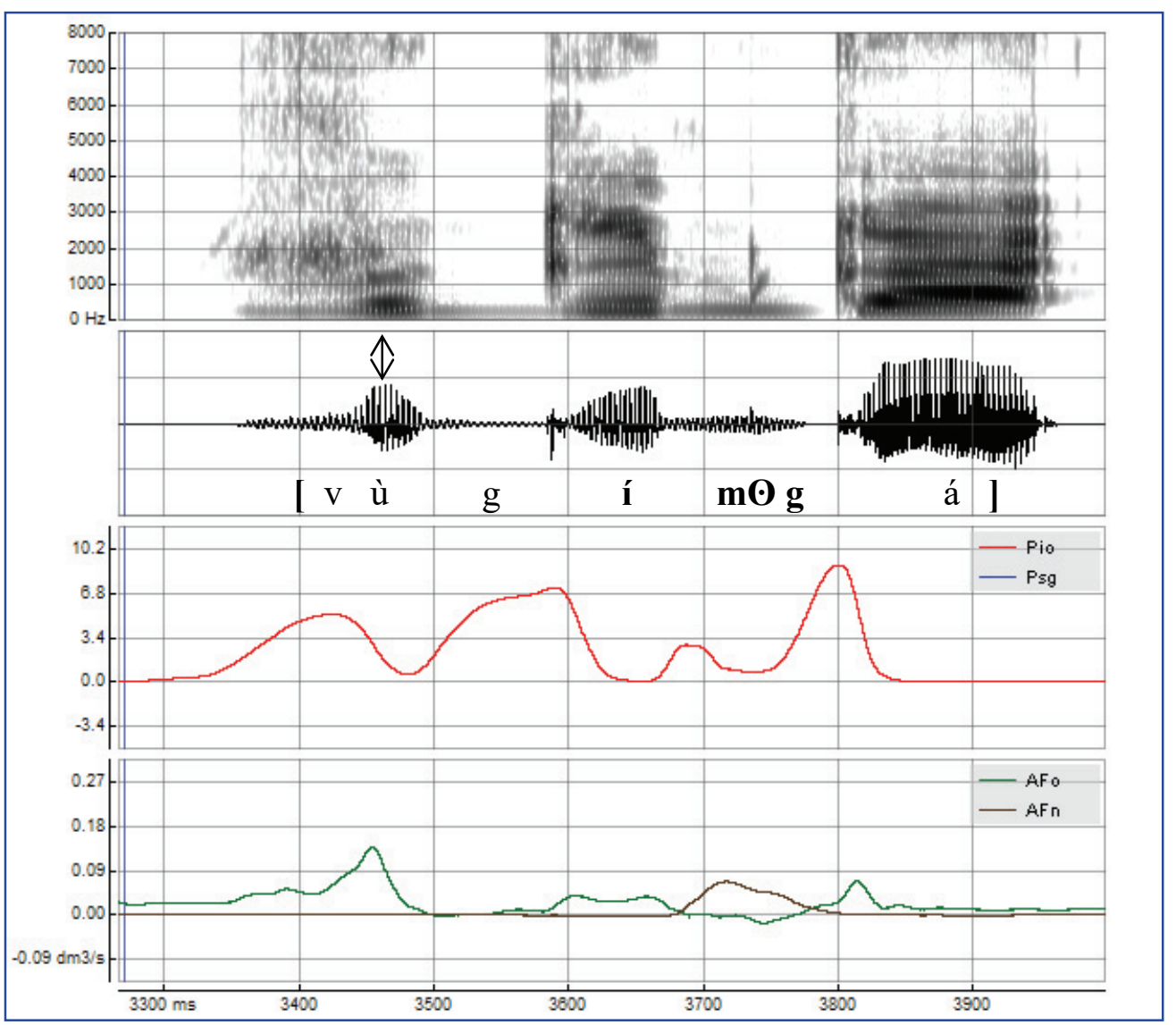

To hear audio click here 
Figure 7. Spectrogram, audio waveform, intraoral pressure (Po), oral airflow (Afo) and nasal airflow (Afn) of the word [ímº́ga.

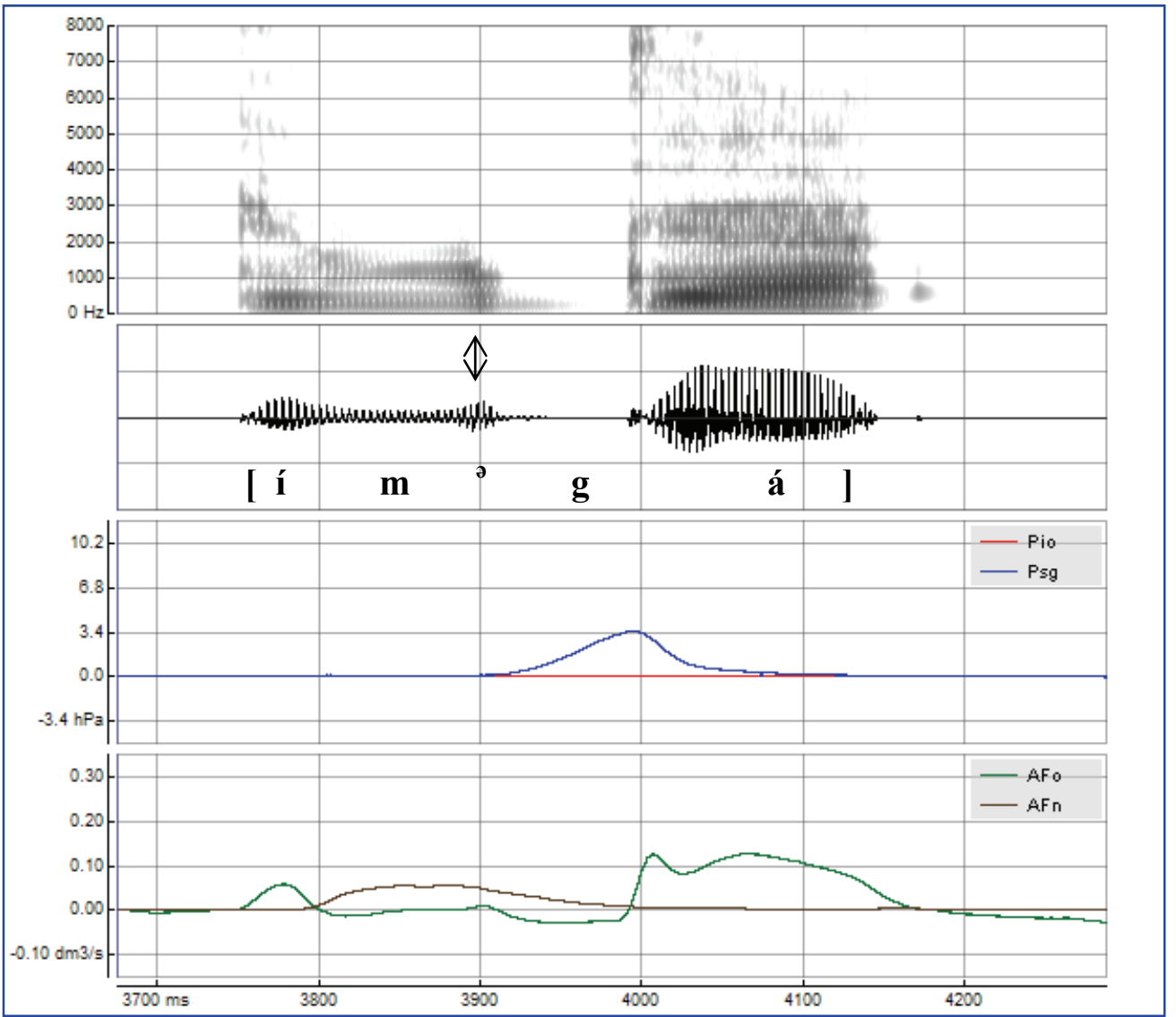

To hear audio click here

3.3.2 Aerodynamics. There is no oral airflow during the sequence in Figure 6. However, a slight decrease can be noticed at the end of the bilabial nasal. Po is rising at the beginning of the bilabial nasal followed by a fall before the burst. Po falls when Afn reaches its peak. Po is then rising for the voiced velar stop. Afo becomes slightly negative a few msec before the click burst appears. This accounts for the tongue moving backwards for the velar stop. Although the negative value of Afo seems weak, it is sufficient to produce a click burst when the labial closure is released. The mechanism is similar to what has been described in 3.1.2. Figure 7 shows that there is no oral airflow during the nasal. After the realization of the small vocoid, oral airflow becomes negative towards the end. Po is rising after the small vocoid. 


\subsection{Prenasalized velars $[\eta \mathrm{k}]$ and $[\mathrm{\eta g}]$}

Figures 8 and 9 show realizations of the words /ínhá/ 'cow' [íná] and /ìngwè/ 'leopard' [ìngwè] that are presented to compare acoustic and aerodynamic parameters of prenasalized consonants with those involving epiphenomenal clicks and emergent vocoids in sequences of [+front] [+back] nasals.

Figure 8. Spectrogram, audio waveform, intraoral pressure (Po), oral airflow (Afo) and nasal airflow (Afn) of the word [ínhá] 'cow'.

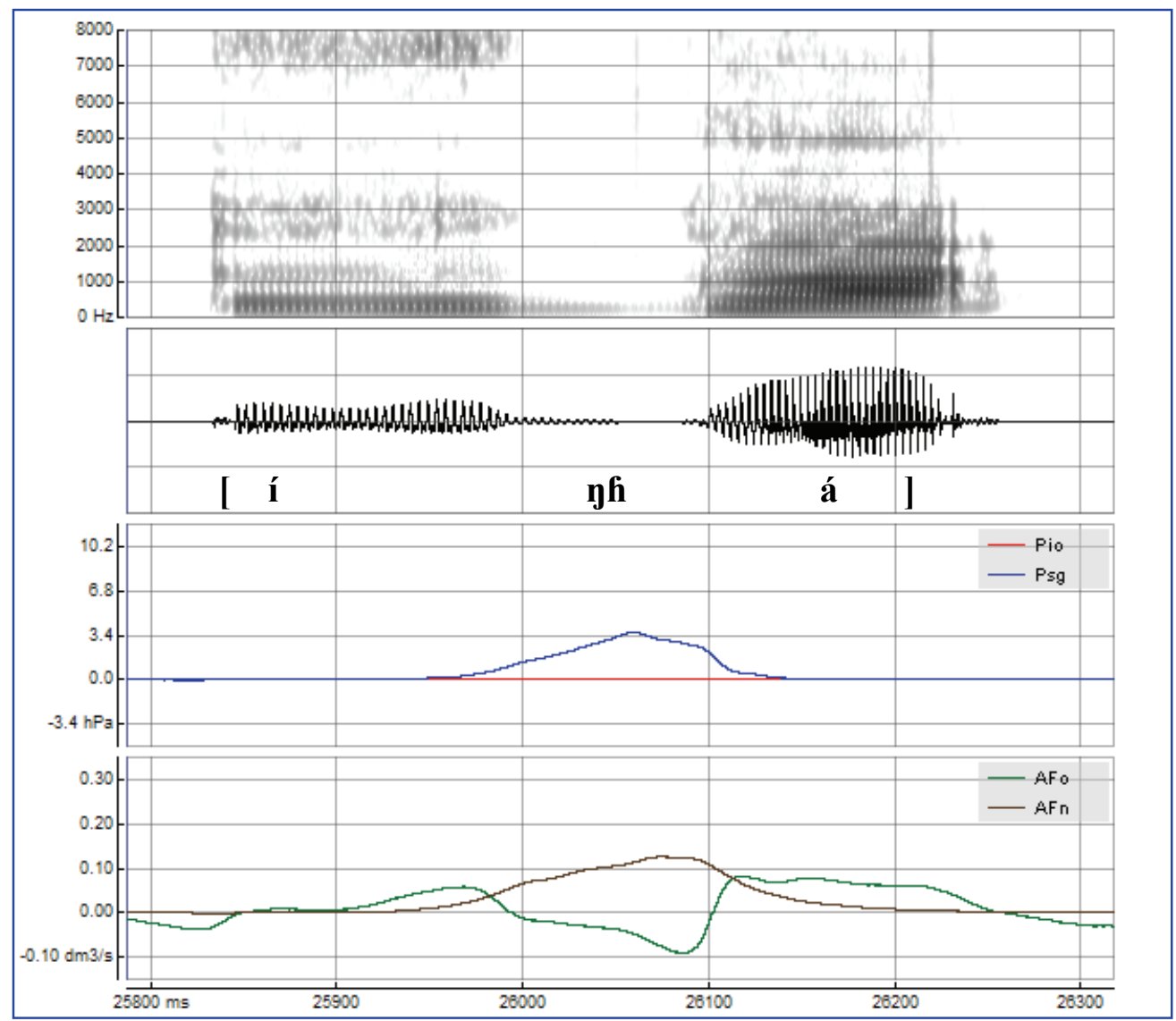

To hear audio click here 
Figure 9. Spectrogram, audio waveform, intraoral pressure (Po), oral airflow (Afo) and nasal airflow (Afn) of the word [ìngwè].

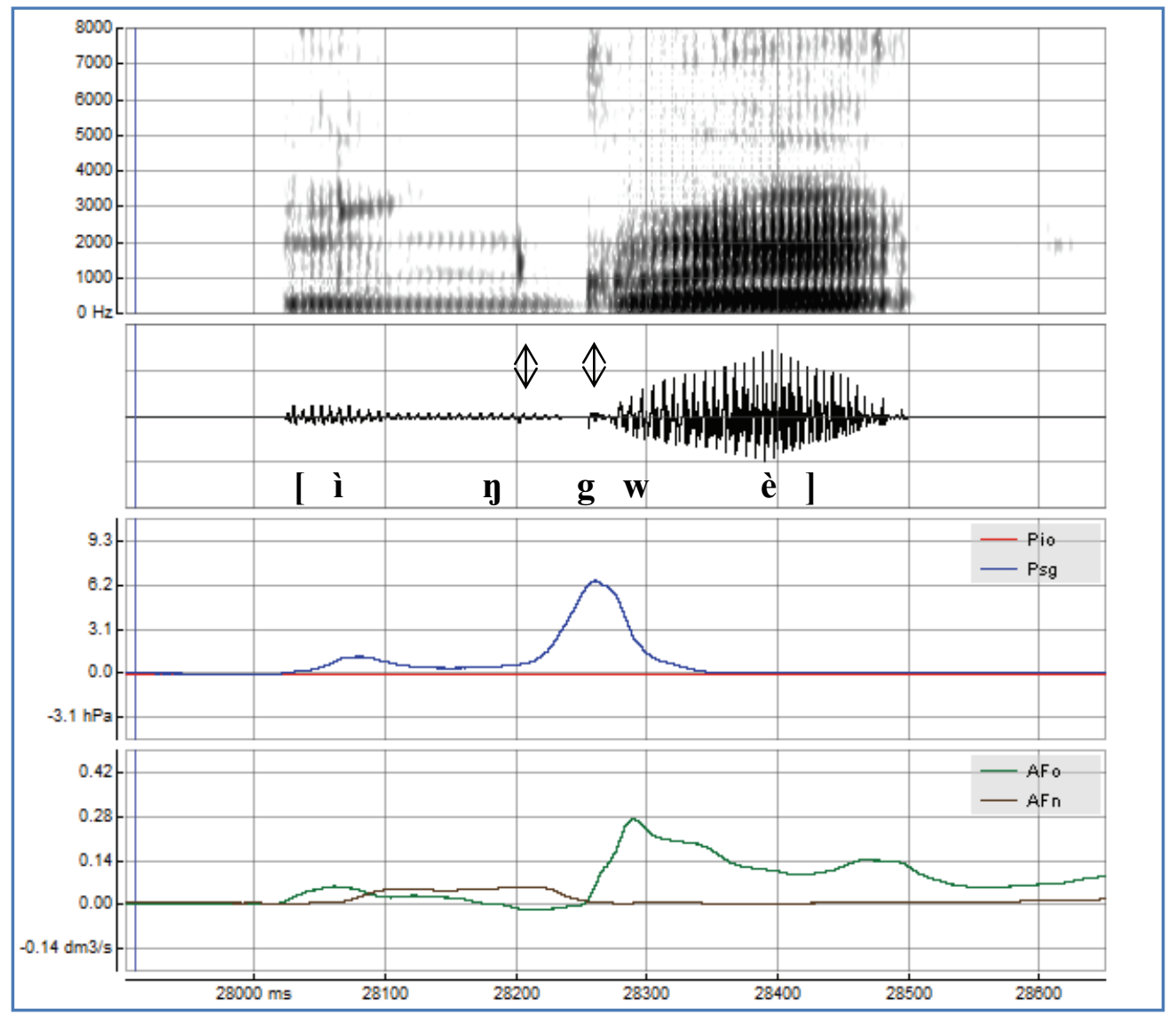

To hear audio click here

3.4.1 Acoustics. Figure 8 shows the realization of the velar nasal, which is usually described as a voiceless prenasalized velar $[\mathrm{yh}]$ in the language, sometimes involving aspiration at the end. ${ }^{4}$ The spectrogram and the audio waveform show a gradual decrease in voicing amplitude but with no interruption. There is a slight aspiration at the end but no distinguishable burst. The aerodynamic parameters show that Po increases of at the same time as Afn. This is not common since normally Po almost equals atmospheric pressure during nasals. Afo also shows a substantial diminution. In the absence of objective articulatory data, one possible explanation is that the concomitant increase of Po and Afn is due to a backward movement of the tongue that gradually diminishes the size of the pharyngeal cavity where Po is measured. This creates an increase in Po and accelerates

4 As mentioned earlier, the data discussed here come from Jouannet (1983). The word for 'cow' is transcribed /ínhá/. In the recorded data speakers produced the aspiration as voiced, i.e. /ínfí/. Coupez et al. (2005) give the transcription /inká/. This disparity might simply reflect the fact that the authors treat different dialects. 
Afn because of the reduction of the velopharyngeal port. The substantial diminution of Afo accounts for the backward movement of the tongue which increases the size of the oral cavity.

Figure 9 shows that there are two visible bursts (indicated by double arrows on the spectrogram and on the audio waveform). The first burst, which covers frequencies below $2500 \mathrm{~Hz}$, is of weak intensity. The second burst which is stronger than the first, marks the release of the oral part of the velar closure in the sequence [ng]. This is present at frequencies below $2500 \mathrm{~Hz}$ and above 5500 $\mathrm{Hz}$ up to $8000 \mathrm{~Hz}$. Phonetically [ng] results from the assimilation of the nasal alveolar prefix [n] to the following velar consonant.

3.4.2. Aerodynamics. Figure 8 shows a gradual increase in Po (up to a maximum of $3.4 \mathrm{hPa}$ ) and nasal airflow during the sequence. At the same time, oral airflow is diminishing gradually. The burst appears at the end of the alveolar nasal where there is also a slight negative oral airflow. Immediately after that, Po increases rapidly and the nasal airflow starts to diminish. Figure 9 shows a slightly negative oral airflow at the end of the alveolar nasal [n], before the velar stop.

\section{Discussion}

As shown above, the sequence [my] can be realized as: [my], [məy, [m९y], $[\mathrm{m} \odot \mathrm{g}]$; the sequence $[n \eta]$ as $[n ! y],\left[n^{\ominus} \eta\right]$. These variations come from differences in the timing and coordination of the labial, alveolar, dorsal and velic gestures involved. When gestures overlap in the front/back nasal sequence and if the front closure is released before the back velar closure, a burst appears. This is in fact a click burst but with weaker intensity compared to Khoisan clicks. The click bursts are homorganic with the first nasal. If the two gestures involved in the front-to-back nasal sequence do not overlap and if a small delay occurs before the velar closure, then a small vocoid $\left.{ }^{\circ}\right]$ appears between the two nasal consonants.

The slight negative airflow occurring in the middle of the [m๑n], [n! $\mathrm{n}]$ nasal clusters observed in Figures 2 and 4 and after the bilabial nasal in the sequence $[\mathrm{m} \odot \mathrm{g}]$ is the consequence of an expansion of the cavity between the two closures. The diminution in Po observed in Figures 4 and 6 does not account for this expansion since it is measured behind the velic closure in the pharyngeal cavity. The presence of a click burst is due to the ingressive influx following the front closure release (either [m] or [n]). Since the pressure in the oral cavity, the cavity anterior to the velic closure, was not measured, Afo is the only parameter that permits inferring an ingressive influx. The latter is the consequence of some expansion of the oral cavity. If there were no expansion, Afo would be positive at the release of the most anterior articulation in the sequence.

Data presented in Figure 8 show that after the beginning of the velar closure, which is accounted for by a gradual increase in Po (up to $3.5 \mathrm{hPa}$ ), there is a gradual increase of nasal airflow. At the same time, oral airflow becomes gradually negative (down to $0.98 \mathrm{dm} 3 / \mathrm{s}$ ). This reflects a lowering and backing movement of the tongue anticipating the following vowel [a] that is rather produced as [a]. The aerodynamic settings of the word [ínhá] are rather unusual because Po and Afn increase at the same time. Understanding this particular fact requires a better comprehension of the articulatory coordination between the tongue and velum movements. The aspirated character of the release might seem doubtful but auditorily it is quite obvious. Data showed that in some cases the phonetic realization of the word [ínfí] is produced with a strong voiced aspiration at the end (see Demolin \& Delvaux 2001 for details). 
When vocoids occur after bilabial or alveolar nasals, it is always possible to observe an increase of oral airflow before the realization of the velar nasal for which there is no oral airflow. Sometimes, as in Figure 5, there is a diminution of the oral airflow, which can even become negative. This reflects the backing movement of the tongue, which is required to articulate the velar nasal.

Data from this paper show that differences in timing and coordination of articulatory gestures found in some of Kinyarwanda's complex consonants trigger acoustic features that have potential consequences at the phonetic and phonological levels. Indeed the emergence of vocoids seems to enhance the fact that due to a difference in timing, the two components of the sequence are maximally differentiated. They remain however in the same syllabic constituent. In the case of the nasal sequences [my] and [ny], the consonants create a complex onset.

In Rwanda, the word for 'dog' /ímbgá/ has several possible (free) variants: [ím@gá], [ímº́n], and [ímbgá]. These variations are presented in Figure 10 with gestural scores. It can be seen that the main difference between the two variants comes from the overlap or separation between the Lip and Tongue body (TB) gestures. In the first case, the release of the bilabial nasal occurs before the velar. This is a mechanism similar to what happens in the production of clicks. The aerodynamic data, even in the absence of oral pressure measurements independent from Po, confirm this point as a slight negative airflow is observed between the bilabial nasal and the velar stop.

The second case where a small vocoid emerges is accounted for by the fact that the release of the bilabial nasal occurs before the velar closure takes place. It is during this short interval of time that the vocoid emerges. 
Figure 10. Gestural scores for [ím®gá] and [ímª́d showing the timing of Lips, Tongue Body (TB), Velum and Glottal gestures. The first arrow in each score indicates the bilabial release. The second the end of the velar closure in [ím@gá] and the beginning of the velar closure [ímº́n].

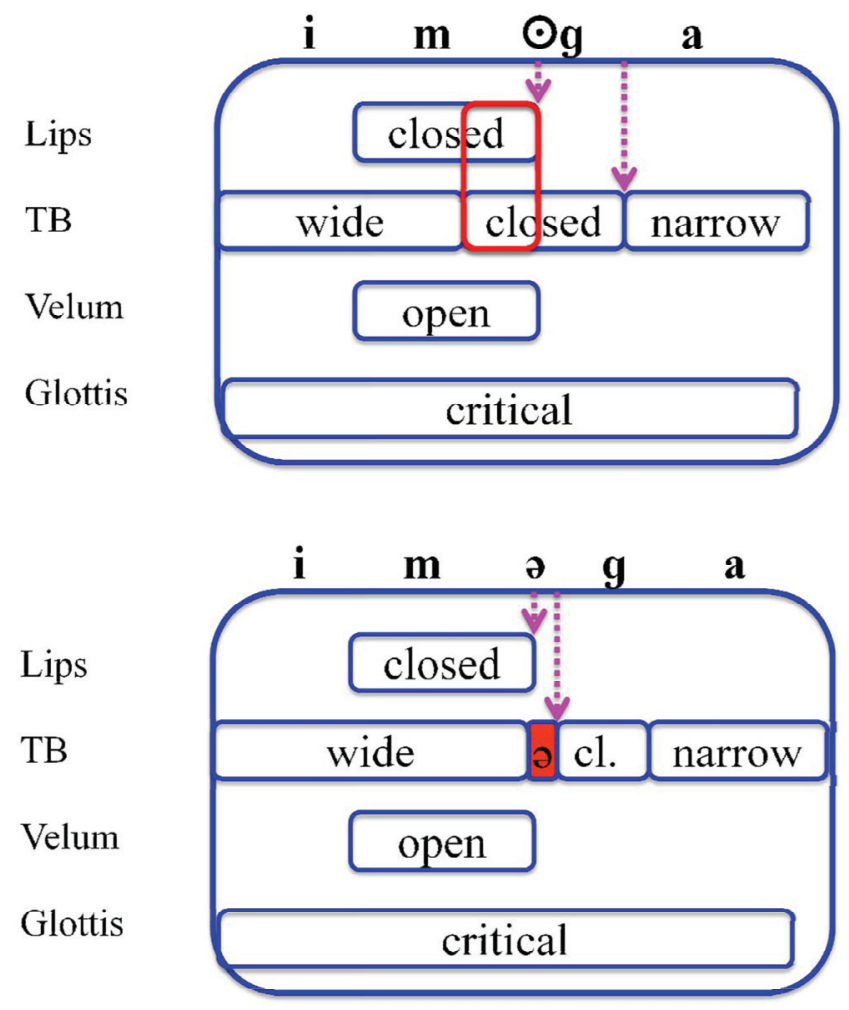

Variations in Kinyarwanda reflect diachronic processes observed in Bantu languages more generally. Indeed this is similar to what happens in Eastern dialects of Shona where /ímgá/ has the following variants: [íbyá], [ímº́a], [ímbgá], [ím@gá] (Doke 1931). This also reflects a process of velarization, which is a well-known evolution from Proto Bantu: *n-buá $>$ m-bwá $>$ m-byá $>$ mbgá. Therefore, data presented in Rwanda reflect a phenomenon that is not limited to Rwanda alone. The occurrence of clicks homorganic to the first nasal in a cluster, where the first is bilabial or alveolar and the second velar, might be confused with the bursts of stops. This is because click bursts produced in Kinyarwanda nasal clusters are of a weak intensity that can be confused with stops bursts.

Emergent bursts were already mentioned a number of times in the literature, e.g. by Marchal (1987) in French and Ohala (1995) in Indo-European languages. Thus, the case of Kinyarwanda is not uncommon except for the fact that it appears in nasal sequences.

The presence of bursts, i.e. of epiphenomenal clicks, between sequences of front and back nasals, where both consonants partially overlap and where the front articulation is released first, thus creating a velaric airstream, is possibly an interesting fact to understand the presence of clicks 
in the Bantu languages that borrowed these sounds. Traill (1995) and Traill and Vossen (1997) suggested an acoustic similarity between the burst of clicks and stop consonants. From an acoustic perceptual point of view, clicks (at least the [+ abrupt]) are bursts of stronger intensity when compared to the release of stops. In this perspective, it is interesting to note that the acoustic output of the (epiphenomenal) alveolar click [!] found in Kinyarwanda, is easily confused with the voiceless alveolar consonant [t].

Note also that in Coupez et al. (2005) there are voiceless stops transcribed in sequences of front nasals followed by velar consonants which is where the epiphenomenal clicks appears in the data presented here. This is shown in the following comparison between our data (transcribed phonetically) and those of Coupez et al. (2005) where prefixes are added: [ìmhyèm@jè], imhweempwe 'chest hair'; [ín!nhwârò], intwáaro 'weapons'; [ín!nwârà], indwáara 'illness'; [ín!nhwânò], inkwáano 'dowry'.

If by a mechanism of amplification, which is quite common in sound change processes and language contact, the burst is strengthened that could lead to the categorization of clicks. Traill \& Vossen (1997) discussing the phonetic basis of click replacement and click loss, note that the auditory effect of the abrupt click influxes [!, ‡] may be quite variable in sharpness and intensity. They also note that this 'click weakening' or acoustic attenuation and click replacement appear to be closely correlated phenomena. There is thus the possibility for the weak burst of epiphenomenal clicks to be amplified or strengthened. In this case the acoustic output might be a click. Even if we cannot conclude that the phenomena presented here is a plausible source of clicks in Bantu, it allows, however, making this hypothesis that should be tested in the future.

Herbert (1990a and 1990b) presents a broad discussion of the sociohistory of clicks in Southern Bantu. In his discussion of the factors accounting for the incorporation of clicks into Bantu phonological systems he mentions the very distinctive acoustic quality of clicks. For Herbert: 'the distinct quality of clicks and the absence of any inherited Bantu sound types with which they matched all contributed to their borrowing'. He then adds in a note that "non-"click incorporating" languages in the area have occasionally managed to nativize clicks, usually by substituting velars. Such a substitution would not be surprising given the essential role of the velum in the production of clicks'. This is a context very similar to what is observed in the occurrences of epiphenomenal clicks in Kinyarwanda. In addition, Herbert (1990a) mentions a point that had already been mentioned by Faye (1923-1925) about categories of consonants substitutions in Zulu. One of them concerns the substitution: 'click for non-click'. Some examples suggest contexts similar to what is observed in Kinyarwanda, i.e., where clicks appear in sequences of consonants where the second is more posterior than the first. The hypothesis suggested here about the possible change of epiphenomenal clicks into phonemic clicks thus suggests a role of sound change in click borrowing in Southern Bantu languages. This does not rule out, of course, other social factors that are presented by Herbert such as hlonipha, the respectful avoidance practice of women marrying into Nguni families that likely promotes click borrowing.

\section{Conclusion}

Differences in timing and coordination of articulatory gestures found in Rwanda's complex consonants can trigger the emergence of acoustic features having consequences at the phonetic and phonological levels. Click bursts of weak intensity might be confused with stops bursts of 
bilabial and alveolar stops. The emergence of small vocoids in nasal sequences show that they are part of complex syllabic onsets. Rwanda reflects variation and diachronic processes observed in other Bantu languages.

\section{Acknowledgements}

We want to thank Florida Ngulinzira and her family for their great help in collecting the data. Discussions at the conference in Johannesburg honoring Tony Traill in July 2013 made us improve various aspects of the paper as well as exchanges with Maarten Mous and Tucker Childs. This study is also dedicated to the memory of Boniface Ngulinzira who died in the tragic events of 1994 in Rwanda, victim of his tolerance and open mind at a time when extremism of all kinds devastated his country.

\section{References}

Coupez, A., Kamanzi, T., Bizimana, S. et collaborateurs. 2005. Inkoranya y'ikinyarawaanda mu kinyarwaanda nó mu gifaraansá ; Dictionnaire Rwanda-Rwanda et Rwanda-Français. 3 vols. Butare: Institut de recherche scientifique et technologique; Tervuren: Musée royal de l'Afrique centrale.

Demolin, Didier \& Véronique Delvaux. 2001. Whispery voiced nasal stops in Rwanda. In Proceedings Eurospeech. Aalborg. 651-654.

Demolin, Didier. 2007. Coarticulatory timing and aerodynamics of nasals and nasalization. Paper presented at the ICPHS in Saarbrücken.

Doke, Clement M. 1931. A Comparative Study in Shona Phonetics, Johannesburg. University of Witwatersrand Press.

Faye, Carl U. 1923-1925. The influence of 'Hlonipha' on the Zulu clicks. Bulletin of the School of Oriental and African studies, 3. 757-782.

Herbert, Robert K. 1990a. The relative markedness of click sounds: Evidence from language change, acquisition and avoidance. Anthropological Linguistics, 32, 1/2. 120-138.

Herbert, Robert K. 1990b. The sociohistory of clicks in Southern Bantu. Anthropological Linguistics, 32, 3/4. 95-315.

Jouannet, Francis. 1983. Phonétique et phonologie des consonnes du Rwanda, in Jouannet, Francis (ed.) Le Rwanda langue bantu du Rwanda, Etudes linguistiques. Paris. SELAF, 55-73.

Maddieson, Ian. 1984. Pattern of Sounds. Cambridge. Cambridge University Press.

Mathangwane, Joyce T. 1999. Ikalanga Phonetics and Phonology. CSLI Publications. Stanford.

Marchal, Alain. 1987. Des clics en français? Phonetica, 44. 30-37.

Ohala, John J. \& Marjani Ohala. 1993. The phonetics of nasal phonology: Theorems and data, in Huffman, Marie K. \& Rean A. Krakow (eds.), Phonetics and Phonology, volume 5, Nasals, Nasalization and the Velum. San Diego. Academic Press, 225-249. 
Ohala, John J. 1995. A probable case of clicks influencing the sound patterns of some European languages. Phonetica, 52. 160-170.

Teston, B. and Galindo, B. 1990. Design and development of a workstation for speech production analysis. Proceedings of VERBA90: International conference on speech technology. Rome, 400-408.

Traill, Anthony. 1995. The perception of clicks in !Xóõ. Journal of African languages and Linguistics, 15. 161-174.

Traill, Anthony \& Rainer Vossen. 1997. Sound change in the Khoisan languages: new data on click loss and click replacement. Journal of African languages and Linguistics, 18. 21-56.

Didier Demolin

Laboratoire de phonétique et phonologie Université Sorbonne nouvelle

Paris 3
Submitted: 25 March 2015

Accepted: 21 July 2015

Revisions received: 2 August 2015 